\title{
Human papillomavirus (HPV) infection and intraepithelial neoplasia and invasive cancer of the uterine cervix: a case-control study in
} Zaragoza, Spain

\author{
Milagros Bernal1, Isabel Burilloํ, Jose I Mayordomo*2,4, Manuel Moros ${ }^{3}$, \\ Rafael Benito ${ }^{1}$ and Joaquina Gil ${ }^{1}$
}

Address: ${ }^{1}$ Department of Microbiology, Preventive Medicine and Public Health, University of Zaragoza School of Medicine, Zaragoza, Spain, ${ }^{2}$ Division of Medical Oncology, University Hospital, Zaragoza, Spain, ${ }^{3}$ Division of Surgical Pathology, University Hospital, Zaragoza, Spain and ${ }^{4}$ Servicio de Oncología Médica, Hospital Clínico Universitario, Av. San Juan Bosco, 15, 50009, Zaragoza, Spain

Email: Milagros Bernal - mibernal@unizar.es; Isabel Burillo - iburillo@yahoo.es; Jose I Mayordomo* - josemayordomo@hotmail.com; Manuel Moros - mmoros@unizar.es; Rafael Benito - rbenito@unizar.es; Joaquina Gil - jgil@aragon.es

* Corresponding author

Published: 29 May 2008

Infectious Agents and Cancer 2008, 3:8 doi:10.1 186/1750-9378-3-8
Received: 14 January 2008

Accepted: 29 May 2008

This article is available from: http://www.infectagentscancer.com/content/3/I/8

(C) 2008 Bernal et al; licensee BioMed Central Ltd.

This is an Open Access article distributed under the terms of the Creative Commons Attribution License (http://creativecommons.org/licenses/by/2.0), which permits unrestricted use, distribution, and reproduction in any medium, provided the original work is properly cited.

\begin{abstract}
Introduction: The raw incidence of cancer of the uterine cervix is Spain is 7,8 per 100.000 inhabitants (adjusted incidence is 5.6). The incidence of this tumor is still low, but a steady increase has been seen, probably related to increasing risk factors.
\end{abstract}

Aim: To determine the frequency of infection by different types of human papillomavirus (HPV) in Papanicolau smears from women with and without cancer of the uterine cervix in Spain.

Patients and methods: A case-control study was performed in women with and without cervical cancer from Zaragoza, Spain. Pap smears from 600 cases (540 women with cervical intraepithelial neoplasms (CIN) and 60 with invasive cancer) and 1200 controls (women without those lesions) were tested by polymerase chain reaction (PCR) and typed by oligonucleotide microarray-based detection.

Results: HPV was detected in $93.3 \%$ of all samples with invasive cancer versus $17.5 \%$ of controls. OR for invasive cancer was $55(95 \% \mathrm{Cl} 21.5-140,5)$. Statistically significant associations were also found for different grades of cervical dysplasia.

Conclusion: The strong association found between HPV infection, specifically types 16 and 18 and cancer of the uterine cervix in Zaragoza, Spain, stresses the importance of ongoing efforts to institute a vaccine program with recently approved HPV vaccines in order to prevent cervical cancer in this population.

\section{Background}

Cancer of the uterine cervix is more frequent in developing countries than in the Western world. Spain, a country where screening through Papanicolau smears has been performed for more than 30 years now, has a low raw incidence of 7.8 in 2000 (age-adjusted rate is 5.6) [1]. 
In the last decade, an increasing incidence of cervical cancer has been noted, most likely related to increasing numbers of young women with risk factors, namely sexual promiscuity and prostitution.

The fact that these high-risk women, some of whom are foreign immigrants, are not adhering to screening programs, stresses the importance of developing alternative strategies for prevention.

While there are many genotypes of human papillomavirus and most of them are frequently found in Pap smears of healthy women, two genotypes, 16 and 18, of human papillomavirus have been consistently associated to intraepithelial neoplasia and invasive cancer of the uterine cervix in Western populations [2] and have been included in papillomavirus vaccines. However, it must be noted that additional genotypes that are not included in the first generation of human papillomavirus vaccines, that has just been approved for clinical use, are frequently associated to intraepithelial and invasive cervical neoplasia in South America and Asia.

We have performed a case-control study to assess the incidence of infection by different HPV types in women with and without cervical dysplasia and carcinoma. Following PCR-based detection of HPV, oligonucleotide microarraybased detection was used for genotyping, given its reliability and ease of use.

\section{Methods}

Following approval by the Institutional review Board of the University of Zaragoza, the study included six hundred consecutive women with some degree of cervical dysplasia or neoplasia (CIN I, CIN II, CIN III and invasive cancer) excluding atypical squamous cells of uncertain significance (ASCUS) who had Pap smears at the University Hospital of Zaragoza, Spain from 1999 to 2005. Cytological diagnoses were required to have been subsequently confirmed by histology for study entry.

Controls were 1200 age-matched women who had no cervical dysplasia, neoplasia or ASCUS in the Pap smear, for a case:control ratio of 1:2.

In addition to standard cytologic examination, all Pap smears from cases and controls underwent DNA extraction and were tested for HPV by polymerase chain reaction (PCR) and typed by oligonucleotide microarraybased detection [3] with positive and negative controls.

Statistical analysis included a logistic regression analysis adjusted for age, calculating odds ratio (OR) for each type of cervical lesion (CIN I, CIN II; CIN III and invasive can- cer) and 95\% confidence intervals in women with and without HPV positivity in the Pap smear.

\section{Results}

The study population included 1800 women. Median age was 36 years. There were 3.3\% foreign-born individuals. The number of samples in each diagnostic group was: 120 patients (20\%) with CIN I, 210 (35\%) with CIN II, 210 (35\%) with CIN III and 60 (10\%) with invasive cervical carcinoma. All these cytological diagnoses had been subsequently confirmed by histology. The frequency of HPV positivity according to type of cervical lesion is shown in Table 1. Overall, $79 \%$ of cases and $17 \%$ of controls tested positive for HPV. According to the type of lesion, $66 \%$ of patients with CIN I tested positive for HPV, as did 71\% of those with CIN II, 90\% of those with CIN III and 90\% of patients with invasive cervical carcinoma.

As for HPV types (Table 2), the most frequent type of HPV found in women with CIN I, CIN II, CIN III and invasive carcinoma was HPV-16, followed by HPV-18. In patients with CIN, these two genotypes comprised 55\% of HPV infections detected, versus $80 \%$ in patients with CIN II and $90 \%$ in patients with CIN III. In patients with invasive carcinoma, HPV-16 and HPV-18 comprised 98\% of all HPV infections detected.

It is remarkable that HPV 16 and HPV 18 were infrequent among controls, comprising only $1 \%$ of all HPV infections.

Table 3 shows the odds ratio for each type of cervical lesion in women with or without HPV positivity. The odds ratio was higher for high-grade lesions, ranging from 6 for CIN I to 55 for infiltrating carcinoma.

\section{Discussion}

In the present study, the correlation between HPV and cervical neoplasia has been different for early lesions (odds ratio for CIN I = 6; odds ratio for CIN II = 10) than for higher-risk lesions (odds ratio for CIN III = 16; odds ratio for invasive carcinoma $=55$ ).

Table I: Frequency of HPV positivity according to type of cervical lesion found in Pap smears.

\begin{tabular}{ccc}
\hline Pathological diagnosis & Number of patients & Number (\%) HPV + \\
\hline CIN I & 120 & $80(66 \%)$ \\
CIN II & 210 & $150(71 \%)$ \\
CIN III & 210 & $190(90 \%)$ \\
Invasive carcinoma & 60 & $56(93 \%)$ \\
Total cases & 600 & $476(79 \%)$ \\
Controls & 1200 & $210(17 \%)$
\end{tabular}


Table 2: Most frequent HPV genotypes found in the study according to the type of cervical lesion.

\begin{tabular}{|c|c|c|c|c|c|}
\hline \multicolumn{6}{|c|}{ Pathological diagnosis } \\
\hline Genotype found & CIN I & CIN II & CIN III & Invasive carcinoma & No cancer (control) \\
\hline HPV-I6 & $30 \%$ & $30 \%$ & $80 \%$ & $90 \%$ & $1 \%$ \\
\hline HPV-I8 & $25 \%$ & $50 \%$ & $10 \%$ & $8 \%$ & 0 \\
\hline HPV-I & $10 \%$ & $5 \%$ & $0 \%$ & $0 \%$ & $30 \%$ \\
\hline HPV-4 & $0 \%$ & $3 \%$ & $2 \%$ & $0 \%$ & $12 \%$ \\
\hline HPV-3I & $7 \%$ & $6 \%$ & $3 \%$ & $0 \%$ & $49 \%$ \\
\hline HPV-54 & $27 \%$ & $4 \%$ & $2 \%$ & $0 \%$ & $12 \%$ \\
\hline Others & $1 \%$ & $2 \%$ & $3 \%$ & $2 \%$ & $26 \%$ \\
\hline
\end{tabular}

Overall, the odds ratio found in our study is well within values reported in prior articles, ranging from a lowest value of $2(95 \%$ confidence interval $=1.5-2.6)$ in a series of women with cancer of the uterine cervix from the United Kingdom to a high odds ratio of 813 (95\% confidence interval $=168-3229$ ) seen in another study [4]. Other authors found intermediate values, such as 18.5 $(95 \%$ confidence interval $=5.9-57.6)[5]$ and $67.2(95 \%$ confidence interval $=28.6-157.5)[6]$. The odds ratio in women with HPV and coexisting HIV infection was found to be $16.8(95 \%$ confidence interval $=7.0-40.3)[7]$.

Such large differences in studies that are otherwise concordant in showing a significant association between HPV infection and cervical cancer may well be due to differences in the type of pathological lesion, the viral load and the duration of infection.

In a study from Mexico [8], the odds ratio for CIN I in women with low viral load was 16.8 (95\% confidence interval $=7.2-39$ ), while the odds ratio for CIN II and CIN III in women with high viral load was 365 (95\% confidence interval $=94.7-1412$ ) .

In the present study, a higher odds ratio was found for more severe cervical lesions, reaching a maximum of 55 for invasive carcinoma, a figure that is remarkably similar to that found in prior studies.

The fact that HPV detection was performed just after cytological examination, without the long storing periods seen in some prior studies [9] supports the reliability of the present data.

Both HPV-16 and HPV-18 were significantly more frequent in cases than in controls, as seen in prior reports [10-15]. There is a trend to increasing percentage of HPV16 and HPV-18 infections in patients with CIN III (90\%) as compared to those with CIN I (55\%).
An interesting finding in our study is the high prevalence of HPV-54 in controls (12\%) and patients with CIN I $(27 \%)$. The fact that the prevalence of HPV-54 in patients with CIN III and invasive carcinoma was much lower $(0 \%$ and $2 \%$ ) suggests that this type has a low potential to induce invasive cancer.

Prior studies have found other HPV genotypes different from HPV-16 and HPV-18 to be related to cervical cancer in specific geographic areas [16]. That is the case for HPV58 , found frequently in women with cervical cancer in Central and Soutth America [17] and China. This suggests that the distribution of HPV types in women with squamous cell carcinoma is heterogeneous around the world.

As in other studies performed in Spain [18], HPV 16 and 18 are the only genotypes that are significantly associated to intraepithelial and invasive carcinoma of the uterine cervix. It is possible that significant immigration from South America and Asia might result in the appearance of additional oncogenic genotypes not included in current HPV vaccines.

It is remarkable that a significant percentage of healthy women (controls) harbour HPV $(17 \%$ in the present study, similar to prior reports), even if the types were different from women with cervical lesions and the prevalence of types associated with cancer (namely HPV-16 and HPV-18) was very low.

Table 3: Odds ratio for each type of cervical lesion according to HPV status.

\begin{tabular}{ccc}
\hline Type of lesion & Odds ratio & 95\% Confidence interval \\
\hline CIN I & 6.0 & $3.7-9.7$ \\
CIN II & 10.6 & $7.2-15.6$ \\
CIN III & 16.7 & $10.5-26.4$ \\
Invasive carcinoma & 55.0 & $21.5-140.5$
\end{tabular}


The high frequency of HPV found in controls suggests that most were transient infections. Only women infected with high-risk HPV types and with ineffective immune response would develop neoplasia [19-21].

The distribution of HPV types associated to cervical cancer in each area of the world needs to be taken into account when designing HPV vaccines. This is an exciting time for prevention of cancer of the uterine cervix, when two HPV vaccines have already been proven to be effective in preventing cervical cancer, and may soon improve public health strategies against this disease, currently based solely on early detection by Pap smears.

\section{Conclusion}

The strong association found in this report between HPV infection, specifically types 16 and 18 and cancer of the uterine cervix in Zaragoza, Spain, stresses the importance of ongoing efforts to institute a vaccine program with two recently approved HPV vaccines in order to prevent cervical cancer in this population.

\section{Authors' contributions}

$\mathrm{MB}$ and IB designed the study, MM, RB and JG carried out the molecular genetic studies, JIM drafted the manuscript. All authors read and approved the final manuscript.

\section{Acknowledgements}

We acknowledge Fausto Garcia for his continued support.

\section{References}

I. Parkin DM, Whelan SL, Ferlay J, Teppo L, Thomas DB: Cancer in Five Continents. IARC Scientific Publications 2005, VIII:

2. Jastreboff AM, Cymet $T$ : Role of the human papilloma virus in the development of cervical intraepithelial neoplasia and malignancy. Postgrad Med J 2002, 78(9 I 8):225-228.

3. Kim CJ, Jeong JK, Park M, Park TS, Park TC, Namkoong SE, Park JS: HPV oligonucleotide microarray-based detection of HPV genotypes in cervical neoplastic lesions. Gynecol Oncol 2003, 89:210-7.

4. Kjaer SK, Brule AJ van den, Paull G, Svare El, Sherman ME, Thomsen BL, Suntum M, Bock JE, Poll PA, Meijer CJ: Type specific persistence of high risk human papillomavirus (HPV) as indicator of high grade cervical squamous intraepithelial lesions in young women: population based prospective follow up study. BMJ 2002, I 4(325):572.

5. Tachezy R, Salakova M, Hamsikova E, Kanka J, Havrankova A, Vonka V: Prospective study on cervical neoplasia: presence of HPV DNA in cytological smears precedes the development of cervical neoplastic lesions. Sex Transm Infect 2003, 79:191-6.

6. Olsen AO, Gjoen K, Sauer T, Orstavik I, Naess O, Kierulf K, Sponland G, Magnus P: Human papillomavirus and cervical intraepithelial neoplasia grade II-III: a population-based case-control study. Int / Cancer 1995, 6 I(3):3।2-5.

7. Heard I, Tassie JM, Schmitz V, Mandelbrot L, Kazatchkine MD, Orth G: Increased risk of cervical disease among human immunodeficiency virus-infected women with severe immunosuppression and high human papillomavirus load. Obstet Gynecol 2000, 96:403-9.

8. Hernandez-Hernandez DM, Ornelas-Bernal L, Guido-Jimenez M, Apresa-Garcia T, Alvarado-Cabrero I, Salcedo-Vargas M, MoharBetancourt A, Garcia-Carranca A: Association between high-risk human papillomavirus DNA load and precursor lesions of cervical cancer in Mexican women. Gynecol Oncol 2003, 90:310-7.
9. Zielinski GD, Snijders PJ, Rozendaal L, Voorhorst FJ, Linden HC van der, Runsink AP, de Schipper FA, Meijer CJ: HPV presence precedes abnormal cytology in women developing cervical cancer and signals false negative smears. $\mathrm{Br} J$ Cancer 200I, 85(3):398-404.

10. Arora R, Kumar A, Prusty BK, Kailash U, Batra S, Das BC: Prevalence of high-risk human papillomavirus (HR-HPV) types 16 and 18 in healthy women with cytologically negative Pap smear. Eur J Obstet Gynecol Reprod Biol 2005, I 2 I (I): I04-9.

II. Ylitalo N, Sorensen P, Josefsson AM, Magnusson PK, Andersen PK, Ponten J, Adami HO, Gyllensten UB, Melbye M: Consistent high viral load of human papillomavirus 16 and risk of cervical carcinoma in situ: a nested case-control study. Lancet 2000, 355(9222):2194-8.

12. Levi JE, Fernandes S, Tateno AF, Motta E, Lima LP, Eluf-Neto J, Pannuti CS: Presence of multiple human papillomavirus types in cervical samples from HIV-infected women. Gynecol Oncol 2004, 92:225-3I.

13. Khan MJ, Castle PE, Lorincz AT, Wacholder S, Sherman M, Scott DR, Rush BB, Glass AG, Schiffman M: The elevated 10 -year risk of cervical precancer and cancer in women with human papillomavirus (HPV) type 16 or 18 and the possible utility of type-specific HPV testing in clinical practice. J Natl Cancer Inst 2005, 97( (14): 1072-9.

14. Tornesello ML, Duraturo ML, Salatiello I, Buonaguro L, Losito S, Botti G, Stellato G, Greggi S, Piccoli R, Pilotti S, Stefanon B, De Palo G, Franceschi S, Buonaguro FM: Analysis of human papillomavirus type-16 variants in Italian women with cervical intraepithelial neoplasia and cervical cancer. J Med Virol 2004, 74: I I7-26.

15. Arora R, Kumar A, Prusty BK, Kailash U, Batra S, Das BC: Prevalence of high-risk human papillomavirus (HR-HPV) types 16 and 18 in healthy women with cytologically negative Pap smear. Eur J Obstet Gynecol Reprod Biol 2005, I 2 I (I): I04-9.

16. Masumoto N, Fujiii T, Ishikawa M, Mukai M, Ono A, Iwata T, Kubushiro K, Nozawa S: Dominant human papillomavirus 16 infection in cervical neoplasia in young Japanese women; study of 88 I outpatients. Gynecol Oncol 2004, 94:509-I4.

17. Ferrera A, Velema JP, Figueroa M, Bulnes R, Toro LA, Claros JM, De Barahona $O$, Melchers WJG: Human papillomavirus infection, cervical dysplasia and invasive cervical cancer in Honduras: a case-control study. Int J Cancer 1999, 82(6):799-803.

18. Muñoz N, Bosch FX, de Sanjose S, Herrero R, Castellsague X, Shah $\mathrm{KV}$, Meter JF: Epidemiological Classification of human papillomavirus types associated with cervical cancer. $N$ Engl $\mathrm{J}$ Med 2003, 348:5i 8-27.

19. Prusty BK, Kumar A, Arora R, Batra S, Das BC: Human papillomavirus (HPV) DNA detection in self-collected urine. Int J Gynaecol Obstet 2005, 90:223-7.

20. Dannecker C, Siebert U, Thaler CJ, Kiermeir D, Hepp H, Hillemanns $P$ : Primary cervical cancer screening by self-sampling of human papillomavirus DNA in internal medicine outpatient clinics. Ann Oncol 2004, I 5:863-9.

21. Mandelblatt JS, Lawrence WF, Womack SM, Jacobson D, Yi B, Hwang YT, Gold K, Barter J, Shah K: Benefits and costs of using HPV testing to screen for cervical cancer. JAMA 2002, 287(18):2372-8I.

Publish with BioMed Central and every scientist can read your work free of charge

"BioMed Central will be the most significant development for disseminating the results of biomedical research in our lifetime."

Sir Paul Nurse, Cancer Research UK

Your research papers will be:

- available free of charge to the entire biomedical community

- peer reviewed and published immediately upon acceptance

- cited in PubMed and archived on PubMed Central

- yours - you keep the copyright 